Männer und Frauen der Medizin 

O. Helfer $\cdot$ R. Winau

\section{Männer und}

Frauen der Medizin

Illustrierte Kurzbiographien

zur Geschichte der Medizin

6., neubearbeitete Auflage

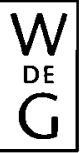

Walter de Gruyter · Berlin · New York 1986 
Dr. med. O. Helfer

Ltd. Med.-Dir. i. R.

Rhumeweg 19

1000 Berlin 37
Prof. Dr. Dr. R. Winau

Institut für Geschichte der Medizin der FU Berlin

Augustastr. 37

1000 Berlin 45

Die 1. - 5. Auflage erschien unter dem Titel ,Männer der Medizin‘.

Bildnachweis: Institut für Geschichte der Medizin der FU Berlin, S. 200 MPG-Archiv

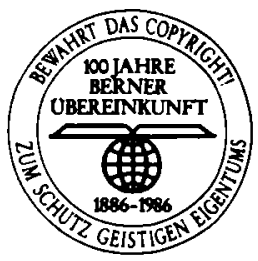

CIP-Kurztitelaufnahme der Deutschen Bibliothek

\section{Helfer, Otto:}

Männer und Frauen der Medizin : ill. Kurzbiographien zur Geschichte d. Medizin / O. Helfer ; R. Winau. - 6., neubearb. Aufl. - Berlin ; New York : de Gruyter, 1986.

Bis 5. Aufl. u.d.T.; Helfer, Otto: Männer der Medizin ISBN 3-11-010543-8

NE: Winau, Rolf:

(C) Copyright 1986 by Walter de Gruyter \& Co., Berlin 30. Alle Rechte, insbesondere das Recht der Vervielfältigung und Verbreitung sowie der Übersetzung, vorbehalten. Kein Teil des Werkes darf in irgendeiner Form (durch Photokopie, Mikrofilm oder ein anderes Verfahren) ohne schriftliche Genehmigung des Verlages reproduziert oder unter Verwendung elektronischer Systeme verarbeitet, vervielfältigt oder verbreitet werden. Printed in Germany.

Satz und Druck: Arthur Collignon GmbH, Berlin.

Bindung: Dieter Mikolai, Berlin.

Umschlagentwurf: Rudolf Hübler, Berlin. 